\title{
IMPLEMENTING TOTAL PRODUCTIVE MAINTENANCE IN NIGERIAN MANUFACTURING INDUSTRIES
}

\author{
M.C. ETI* S.O.T. OGAJI**+ and S.D. PROBERT***
}

*Mechanical Engineering Department, Rivers State University Of Science and Technology, PMB 5080 Nkpolu, Oroworukwo, Port Harcourt, Rivers State, Nigeria ** School Of Engineering, Cranfield University, Bedfordshire MK43 OAL, United Kingdom.

${ }^{+}$Corresponding author

\begin{abstract}
:
Remarkable improvements have occurred recently in the maintenance management of physical assets and productive systems, so that less wastages of energy and resources occur. The requirement for optimal preventive maintenance using, for instance, justin-time (JIT) and total quality-management (TQM) techniques has given rise to what has been called the total productive-maintenance (TPM) approach. This study explores the ways in which Nigerian manufacturing industries can implement TPM as a strategy and culture for improving its performance and suggests self-auditing and bench-marking as desirable prerequisites before TPM implementation.
\end{abstract}

ABBREVIATIONS (commonly employed and used in this text)

$\begin{array}{ll}\text { BSC } & \text { Balanced score-card } \\ \text { CBM } & \text { Condition-based maintenance } \\ \text { FMEA } & \text { Failure modes and effects analysis } \\ \text { JIT } & \text { Just-in-time } \\ \text { LCC } & \text { Life-cycle cost } \\ \text { MLDT } & \text { Mean logistic down-time } \\ \text { Mt } & \text { Maintainability } \\ \text { MTBF } & \text { Mean time between failures }(=1 / \lambda) \\ \text { MTTR } & \text { Mean time-to-repair }(=\tau=1 / \mu) \\ \text { MWT } & \text { Mean waiting-time } \\ \text { OEE } & \text { Overall equipment's effectiveness } \\ \text { PLC } & \text { Programmable logic-controller } \\ \text { PM } & \text { Preventive maintenance } \\ \text { RCM } & \text { Reliability-centred maintenance } \\ \text { RTF } & \text { Run-to-failure } \\ \text { SMED } & \text { Single minute exchange of die } \\ \text { SPC } & \text { Statistical process-control } \\ \text { TPM } & \text { Total productive-maintenance } \\ \text { TPS } & \text { Team problem-solving } \\ \text { TQM } & \text { Total quality-management } \\ \text { ZQC } & \text { Zero quality-control }\end{array}$




\section{GLOSSARY}

Just-in-Time (JIT)

Poka yoke

Single Minute Exchange of Die, (SMED)

Speed

Statistical Process Control (SPC)
Ohno [1] together with Shingo [2] introduced the JIT production process, which was first implemented in the Toyota Manufacturing Company. JIT is a technique for reducing wastage through procedures that establish good communications throughout the production process to ensure that all resources are used optimally. In other words, 'let only the system that needs parts get them, and only in the quantity needed' - i.e. lean management. The process includes mistake proofing for operators -i.e. zero quality control, ZQC (=poka yoke) - that inhibits defects occurring by monitoring process-conditions at source and correcting divergences that could cause defects. Poka yoke concepts result in better quality products and greater participation by workers in efforts to improve processes, products and the company as a whole.

A simple method for trying to prevent defects from occurring, initially introduced for business processes.

This describes the Shingeo Shingo [2] technique of dividing the set-up and change-over procedures into external and internal elements and concentrating on reducing the internal time taken so that less of the equipment's available time is consumed during a change-over. The 'single' here means single-digit number of minutes - i.e. less than ten! SMED or quick changeover techniques have been used in JIT manufacturing processes. Cycle-time reduction resulted in products and services that are better, cheaper and delivered faster, hence reducing the need for large inventories.

In the present context, speed means the rate at which a product is manufactured.

This technique, popularised by Deming [3], is used to isolate (in a process) the controllable aspects from random variations, by means of statistical analysis. With correct information, the staff can establish control within acceptable ranges through manual or automatic monitoring: adjustment data were gathered for each part of the process. The staff learn to analyse what the controls output, which leads to them making creative suggestions for achieving improvements in the design 
Team Problem-Solving, (TPS)

Total productive Maintenance (TPM)
This technique, popularised by Juram et al [4], uses team actions to benefit from the opportunities occurring during a project. This helps reluctant participants to accept improvements, because it involves them in making and accepting recommendations on problems, they know need resolving.

This recently-introduced maintenance strategy for plant and equipment usually involves a change in the mind-set of personnel towards their job responsibilities. It requires commitment to the programme by members of the upper level management team as well as empowering employees to initiate corrective actions for defaulting aspects of the system or process under their jurisdiction [http://www.marshallinstitute.com].

\section{THE PROBLEM}

Maintenance is undertaken to preserve the proper functioning of a physical system, so that it will continue to do what it was designed to do. Its function and performance characteristics not only take account of output, unit costs and effectiveness of using energy, but also such factors as end-product quality, process control, achieved comfort and protection of the employed personnel, compliance with environmentalprotection regulations, structural integrity and even the physical appearance of the productive system.

The quality of maintenance significantly affects business profitability. The factors involved include safety, and customer service, not just plant costs and availability. Increased downtime affects adversely the capability of physical systems by reducing their average rate (i.e. speed) of output, so increasing the operating costs and lowering the average customer's satisfaction with the service [5]. With system availability becoming critical, issues such as reducing operating costs as well as the strategic importance of employing better and, if feasible, optimal maintenance schedules need to be more universally recognised and implemented.

Today's world is one of growing expectations, increasingly onerous regulatory constraints, shifting technological paradigms and apparently endless and urgent reorganisations. Just as each major corporation has evolved a mission statement to help maintain a unified approach despite varying distractions, it is also desirable to develop a mission philosophy and statement to help maintenance staff do likewise. Maintenance serves three distinct sets-the owners, the users of the system, and society as a whole. Owners are usually satisfied if their system generates an adequate and continuing financial return on their capital investment. Users want each asset to continue to do whatever it was designed to do, to a standard of performance, which they consider at least to be satisfactory. Society expect the assets, in which investments have been made, not to fail in ways that lead to threats to public health and safety as well as environment. 
The technology of maintenance is about finding and applying cost-effective ways of avoiding or overcoming performance deterioration. Failure-management techniques include predictive and preventive actions, failure-finding, run-to-failure and changes to the design of the physical asset or the way it is operated. Each category includes a host of options, some of which are far more effective than others. Maintenance staffs not only need to be aware of what these options are, but they also have to decide which are appropriate to their circumstances. Making a wise choice should improve the asset's performance, as well as reduce overall costs. However, making a wrong choice could create new problems while existing ones may worsen. Therefore, the relevant mission statement should emphasise the need to make the most cost-effective decisions from a comprehensive array of pertinent options.

Failures usually attract attention because they can adversely affect output, safety, environmental health, quality of end product, customer service, competitiveness and unit costs. The severity and frequency with which a failure leads to these consequences dictate which failure-management technique is worth applying. Therefore, the mission statement should acknowledge the key role of 'consequence avoidance' in maintenance. The policy should be effective in the use of resources (i.e. people, materials, spares, tools, etc). Hence, the cost of maintenance depends not only on the maintenance staff, but also on the designers and operators of the considered manufacturing system. In the present high-stress, turbulent business-environment, well-run organisations strive continually to enhance their capabilities to create excellent value for the customers by improving the cost effectiveness of the operations. Maintenance is thus a vital support function in business, especially as increasingly large investments are being required in physical assets [6].

Total productive-maintenance (TPM) is a proven and successful procedure for introducing maintenance considerations into organisational activities. It involves operational and maintenance staff working together as a team to reduce wastage, minimise downtime and improve end-product quality. It needs active well-focussed maintenance staff, even when the system is perceived to be working as expected. TPM builds on the concepts of just-in-time (JIT), lean management, total qualitymanagement (TQM) and design to achieve minimum life-cycle cost (LCC): it has spread from manufacturing to the process (such as petro-chemical) industries, and possesses the potential to be used in people management as well as generally for improved resource-use.

Many industries in Nigeria operate productively for less that than 50 percent of even the nominally-functioning hours per year. Part of this embarrassment is caused by high downtime, supply failures for input resources, and low spare-capacity to cope with sudden high demands.

TPM focuses on optimising planning and scheduling. Availability, performance and yield (i.e. acceptable quality-rate) are other factors that affect productivity [7]. Availability losses result from breakdowns and change-overs, i.e., the situation in which the line is not running when it should be. Performance losses arise from speed losses and small stops or idling or empty positions. In this case, the line may be running, but it is not producing the quantity it should. Yield losses consist of losses due to rejects and poor start-up behaviour in the line producing the products. These losses lead to low values of the overall equipment's effectiveness (OEE), which 
provides an indication of how effective the production process is. TPM helps to raise the value of the OEE by supplying a structure to facilitate the assessment of those losses, and subsequently giving priority to dealing with the more serious offenders. Application of TPM leads to both short- and long-term improvements.

TPM entails having a:

- Leaner organisational structure (i.e. fewer managers as well as delegating power and responsibility to individual members of the team).

- Multi-skilled workforce

- Rigorous reappraisal of the way things are done now and so improvements are introduced-often resulting in simplification, standardisation and/or harmonization.

TPM seeks to encourage the setting of ambitious, but attainable, goals for raising the value of the OEE and to measure any deviations in what is achieved relative to the original objective.

\section{LITERATURE REVIEW}

The concept of TPM originated in Japan's manufacturing industries, initially with the aim of eliminating production losses due to limitations in the JIT process for production operations [8]. Seichi Nakajima is credited with defining the fundamental concepts of TPM and seeing the procedure implemented in hundreds of plants in Japan; the key concept being autonomous maintenance [9].

TPM is a major departure from the "you operate, I maintain" philosophy [10]. It is the implementation of productive maintenance by all associated personnel (whether machine operators or members of the management team), based on the involvement of all in the continual improvement of performance. TPM endeavours to eliminate the root causes of problems, through team-based decisions and their implementation. Achieving low-cost improvements and zero-deficit product quality are striven for, while designing for minimum LCC maintenance and using the JIT procedure. All employees through small-group activities, which include aiming for zero breakdowns and zero defects, should implement it. The three components of the concept are: (i) optimised equipment-effectiveness, (ii) autonomous-operator maintenance and (iii) company-led small-group activities, throughout the entire organisation. This is a "high-employee involvement" approach. It leads to improved creative group-efforts, greater individual effort, personal responsibility, and lively innovative problemsolving meetings. TPM concepts involve commitments to long-range planning, especially on the part of senior management. Typically, TPM is initiated as a "topdown" exercise, but only implemented successfully via "bottom-up" participation. However, consensus building may take about three years, from the planning phase, for sustainability to be achieved in a large organisation.

TPM is a manufacturing-led initiative that emphasises the importance of (i) people with a 'can do' and continual improvement attitude and (ii) production and maintenance personnel working together in unison. In essence, TPM seeks to integrate the organisation to recognise, liberate and utilise its own potential and skills [11]. 
TPM combines the best features of productive and PM procedures with innovative management strategies and encourages total employee involvement. TPM focuses attention upon the reasons for energy losses from, and failures of equipment due to design weaknesses that the associated personnel previously thought they had to tolerate.

Autonomous maintenance looks into the means for achieving a high degree of cleanliness, excellent lubrication and proper fastening (e.g. tightening of nuts on bolts in the system) in order to inhibit deterioration and prevent machine breakdown. The Japanese Institute of Plant Maintenance in 1996 introduced autonomous maintenance for operations as a role for all employees' in order to achieve greater financial profits.

The aim of TPM is to bring together management, supervisors and trade union members to take rapid remedial actions as and when required. Its main objectives are is to achieve zero breakdowns, zero defects and improved throughputs by:

- Increasing operator involvement and ownership of the process.

- Improving problem-solving by the team.

- Refining preventive and predictive maintenance activities.

- Focussing on reliability and maintainability engineering.

- Upgrading each operator's skills.

The TPM strategy includes:

- Maximising equipment effectiveness.

- Improving quality, increasing safety and reducing costs.

- Raising the morale of the team that is implementing TPM.

The uppermost echelon of management should be highly committed to the setting of wise TPM goals, achieving sustainability, standardisation, pertinent education and training in TPM, measuring TPM effectiveness, developing an autonomous maintenance programme and implementing Kaizen-teian programmes. Workshop management is responsible for implementing TPM goals via group PM, small-group activities, maximising equipment effectiveness, zero-accident and zero-pollution aims, improving operating reliability, reducing the LCC, and problem solving.

Benefits

TPM helps organise maintenance activities by applying the following actions [8]:

- Cultivate a sense of ownership in the operator by introducing autonomous maintenance - the operator takes responsibility for the primary care of his/her plant. The tasks include cleaning, routine inspection, lubrication, adjustments, minor repairs as well as the cleanliness of the local workspace.

- Use cross-functional teams consisting of operators, maintainers, engineers and managers to improve individual employee and equipment performances.

- Establish an optimal schedule of clean-up and PM to extend the plant's lifespan and maximise its uptime.

Many TPM operators have achieved excellent progress [11], in instances such as:- 
- Wiser assessments of and improvements in the performance of critical equipment, e.g. in terms of OEE and determining what are the reasons for any non-achievement.

- Better understanding of the equipment's criticality and where and when is it financially worth improving.

- More cooperative teamwork e.g. less adversarial or competitive approaches between production and maintenance workers.

- Improved procedures for (i) change-overs and set-ups, (ii) carrying out maintenance tasks and (iii) better training of operators and maintainers: all of these lead to reduced unit costs of production and better service.

- Increased enthusiasm, loyalty and involvement of the workforce.

Implementation of TPM forces fundamental rethinks of business processes to achieve lower unit costs, higher quality of end-product and more rapid production.

Robert [10] concluded that TPM brings maintenance into focus as a necessary and vitally important part of the business: maintenance should no longer be regarded as a non-profit-making activity. Downtime for maintenance is scheduled as an on-going activity of the manufacturing process making it imperative to carry out maintenance not solely when there is a failure in the production flow. The goal is to minimise the frequency and magnitudes of emergency and unscheduled maintenance interruptions. Hughes [12] pointed out that the profit-focussed approach to maintenance requires:

- Frequent maintenance and breakdown-prevention measures implemented.

- Training to improve the pertinent skills of all personnel

- Higher effectiveness sought in newly-purchased equipment.

Automated factories are expensive - the consequences of a breakdown or malfunction are usually much more costly than in traditional plants. High machine-utilisation is critical: achieving a high productivity depends on keeping the equipment functioning at peak levels, for as long as is feasible. Today, with competition increasing, successful TPM may be one of the essential factors that determine whether some organisations, survive.

Integrated automated plants require overseeing by pertinently-skilled, flexible and committed workers. High levels of competence are consistent with exalted involvement, employee participation, and self-managing teams. TPM prepares the plant to meet the challenge of a competitive global-economy. Hence, the overall outcome of TPM activities should improve the

- Overall plant's productivity (i.e. more effective operation and resource utilisation as well as the elimination of excessive inventory stocks).

- Rate of throughput (by quicker action/reaction to failure symptoms so leading to reduced downtimes).

- End-product quality (e.g. by insisting on purchasing better designs) and services (e.g. through better-maintained plant and machines).

- Education and training of employees, so empowering them and raising morale, to keep pace with the complexity of evolving technologies. 
The process identifies the non-value-added activities within an organisation and then systematically creates solutions to eliminate successively the most wasteful ones.

Maintenance affects all aspects of business effectiveness - risk, safety, environmental sustainability achieved, energy efficiency, product quality and customer service, i.e. not just plant availability and costs. Downtime has always affected adversely the capability of physical assets by reducing output, increasing operating costs and lowering customer service [5].

Employee empowerment is desirable in order to create excellent commitments amongst the concerned personnel: for this, management, within the overall aims of the organisation, must involve employees in setting challenging targets and specifying how to achieve them. Autonomy is the core concept of empowerment, while the management retains control through information systems, choice of processes and available tools [13].

In a culture that stresses participation and autonomy, the function of the management should not be solely to control but also to provide support and encouragement. Decisions on broadly-based issues, such as the implementation of TPM and RCM or the introduction of a new reward convention for employees, are made only after the management has entered into a dialogue with those affected. The managers will provide overall direction for the work that is clearly targeted and engaging. Their tasks will be those of consultants, mentors and coaches to help the employees avoid unnecessary waste of effort so that they can (i) increase their task-relevant knowledge and skills, and (ii) formulate creative, unique and appropriate performance strategies that generate synergistic process gains. They should also be responsible for answering requests from employees to ensure that the resources required for increasing performance are available when needed.

Communication is an exchange of information and understanding between two or more persons or groups. Communication should be in the recipients' language and within his/her understanding: therefore the message must be in terms of that individual's experience and perception. Management processes, including training should be designed from the point-of-view of the recipient and with a built-in mechanism for feedback. Employees must be encouraged to set measurable but attainable goals. Employee training should focus on appropriate multi-skills and knowledge. Empowerment of employees by devolved authority to make decisions autonomously (i.e. subsidiarity) regarding TQM, so that each individual "owns" the particular process phase, is necessary. The objective throughout is continual improvement.

The application of work measurement in maintenance is likely to generate significant productivity improvements and cost reductions. Nevertheless, maintenance does not normally receive the reasonably proportionate amount of attention that it deserves.

Assessing the effectiveness of a maintenance schedule is complicated because of the multiple interactions involved. Hence, it is common practice to measure individual aspects of maintenance performance [8]. The commonly used maintenance performance indicators [14] are measures of :-

- Equipment performance, such as availability, reliability and OEE. 
- Process performance, such as the ratio of planned and unplanned work, as well as of schedule compliance.

- Cost performance, such as labour and material costs of maintenance

These diagnostic measures [15] will provide indications of whether the various aspects of maintenance operations are effective or compare favourably with those applied elsewhere. Thus, they are used largely to support operational control and benchmarking processes. However, these generic measures do not provide information for predicting the plant's ability to create the future value needed to support the business success of the organisation. This purpose is achieved when the performance measures are linked to the espoused strategy of the maintenance functions, known as strategic measures. Tsang [16] described the process for managing maintenance from a strategic perspective as shown in Figure 1.

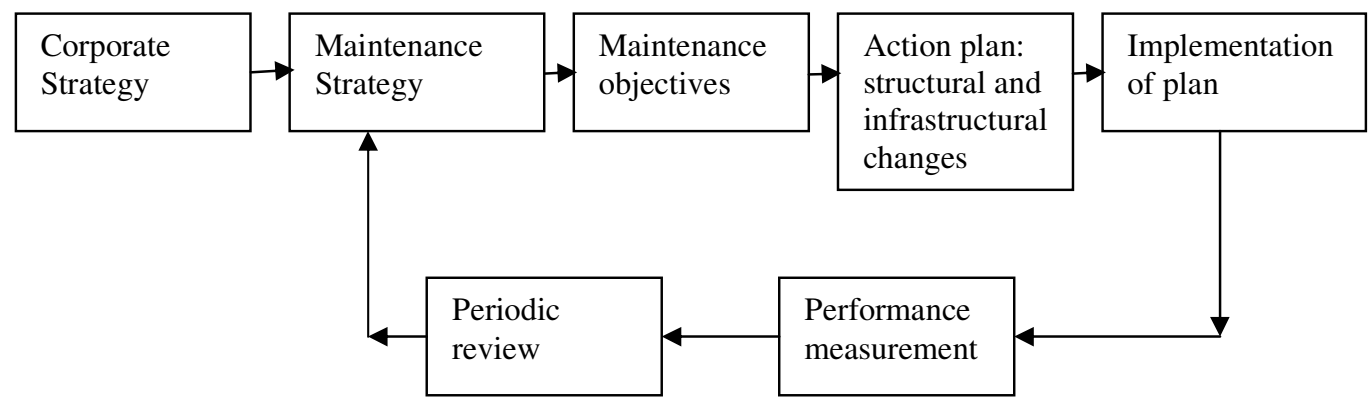

Figure 1: Strategic maintenance-management process

A core feature of the process is the balanced score-card (BSC) that provides a comprehensive presentation of strategic performance measures with respect to four perspectives: (i) financial, (ii) customer, (iii) internal processes, and (iv) learning and growth [17]. When the BSC is used, the strategy is translated into something more tangible, e.g. actionable long-run (strategic) objectives, the related performancemeasures and their targets, as well as action plans.

The performance indicators will highlight opportunities for improvement within companies. Performance-improvement measures should highlight any 'soft spots' in a company, then enable further analysis to find what is causing the associated low values of the indicators, and so ultimately point to a solution to the problem. One of the performance measures should be taken at the corporate strategic level. A second level would be the financial indicator for a particular department or process. A third level would be an effectiveness indicator that highlights the departmental functions that contribute to the effectiveness of the department. The fourth indicator is the measurement of the actual function itself.

TPM does not provide a quick or easy solution. It usually requires changes in employees' attitudes and values, which take time to imbibe. Therefore, it demands thinking for the long term and careful planning. Quick and company-wide performance gains should not be expected during the initial phase [8]. However at this early stage, top management must demonstrate their total commitment to TPM by allocating the necessary resources to create and sustain the cultural changes necessary 
to provide relevant training to employees in order to achieve autonomous maintenance.

. Experience shows that wise planning and propitious timing of the associated actions are vitally important. To reduce uncertainty and enhance the chances of success during the initial phase, small-scale pilot projects can be used to fine-tune plans for the subsequent full-scale implementation [18].

To apply TPM concepts successfully to plant-maintenance activities, the entire workforce must first be convinced that the top-level management is committed to the programme. The senior management team sets company-wide PM policies; that is, placing goal-setting central to the TPM programme promotional structure and committees. The middle management oversees the departmental polices, goal-setting and departmental PM promotional committees. The shop-floor management sets the PM goals according to team groups' activities. In all, this will involve design, operation, maintenance, engineering and sales activities, and may require hiring or appointing a TPM coordinator whose responsibility is to advocate through an educational programme the TPM concepts to the workforce, and check that they are being implemented. As soon as the coordinator is convinced that everybody involved has bought into the idea of the TPM programme, a study and action team is formed and consists of representatives from those who directly have an impact on the problem being addressed. Operation and maintenance staff, shift supervisors, schedulers and top management might all be in the team. Each person becomes a "stakeholder" in the process and is encouraged to do his or her best to contribute to the success of the team. Usually, the TPM coordinator heads the team until others become familiar with the process and a team leader should then emerge naturally [10]. The action teams are charged with the responsibility for pin-pointing the problems, indicating the remedial processes and in particular detailing a course of corrective actions. Sometimes, it may even be worthwhile for team members to pay visits to nominally-similar plants that have attained world-class standards in order to observe TPM methods, techniques and observe work in progress.

The teams are encouraged to start on small problem-solving projects and keep meticulous records of their progress: once the teams are familiar with the TPM methodology and achieved success in overcoming small problems, other more complex enigmas can be tackled.

What then are best practices? How does one enterprise begin to benchmark other companies to help them achieve best practice within the organisation? How does an industry come to know it has achieved world-class status? A definition of best practice, adapted to the maintenance process, is "the integrated maintenance practices that enable a company achieve a competitive advantage over its competitors in the maintenance process". Specifically, benchmarking is the practice of measuring performance against a preset standard. Benchmarking is used by industries to learn about practices that have been proven to lead to superior performances and then to adopt them into their own organisational process. McQueen [19] suggested three types:

- Internal benchmarking, whereby multiple-plant organisations set companywide standards for each of the sites to follow, and then charts each site's performance relative to those standards. 
- Industry benchmarking, where a company's performance is measured against those of other organisations in the same industrial sector..

- Best-practice benchmarking, via which performance is measured against those of other companies considered to be the leaders of that industry, regardless of the end product or provided service of the particular business.

Benchmarking is performed preferably after a detailed internal audit has been conducted.

\section{OTHER MAINTENANCE-OPTIONS}

\section{Reliability-Centred Maintenance (RCM)}

RCM is a process used to decide what must be done to ensure that any physical system or process continues to accomplish whatever its users want it to do. What is expected is defined in terms of primary performance parameters, such as output, throughput, speed, range and capacity. Sometimes, the RCM process defines minimum standards which the users can tolerate in terms of risk (relating to safety and adverse environmental-impact), quality (in terms of precision, accuracy, consistency and stability), control, comfort, economy and customer service. This is followed by identifying ways in which the system can fail to live up to these expectations (i.e. failed states), and then by undertaking a failure modes and effects analysis (FMEA) identify the events which are acceptable, and seek to identify an appropriate failuremanagement policy for dealing with each failure mode in the light of its consequences and technical characteristics. Failure management options include PM, predictive maintenance, and run-to-failure, which can result in changing the design of the system and/or the way it is operated [5].

Preventive Maintenance (PM)

In this kind of maintenance, items are replaced or restored to their optimal working condition before a failure is allowed to occur. The policy can be based on scheduled, time-based or condition-based PM. In the former approach, PM is performed on the item at a scheduled time regardless of its actual state of deterioration. The schedules can be based period of usage or cycle time. The schedule is often drawn up on the supplier's recommendation, which usually only considers limited knowledge of the actual local conditions. Therefore, it is often better to draw from experience. PM schedules that minimise resource consumption or maximise availability can be determined with quantitative decision-models. Parameters featured in these models are information, such as time-to-failure distribution, costs of intervention (inspection, repair or replacement) and consequences of failure.

\section{Condition-Based Maintenance (CBM)}

Under the regime of scheduled PM, some items may be over-maintained, that is replaced prematurely, i.e. before they have suffered significant deteriorations. However, if the condition of the component can be monitored continuously or intermittently but sufficiently, it will be possible to carry out PM actions only when a failure is judged to be imminent [8]. This is the concept of CBM. Performance parameter analysis, vibration monitoring, thermography, oil analysis and ferrography 
are some of the condition-monitoring techniques that are employed in CBM. Each of these methods is designed to detect a specific category of faults. For example, vibration monitoring can detect wear, imbalance, misalignment of components, loosened assemblies or turbulence in a plant with rotational or reciprocating parts.

The design can be modified to achieve improved reliability, enhanced maintainability, minimum maintenance resource requirements and so even eliminate the need for routine maintenance.

Under the run-to-failure (RTF) approach, only routine servicing is performed on the item until it fails. This can be justified when the affect of failure is inconsequential or the cost of preventive measures would exceed the expected benefits of improved reliability of higher availability.

Condition Monitoring

Non-destructive testing, vibration measurement, thermography, ferrography and spectroscopy make it possible to undertake non-intrusive inspections. By applying these technologies, the condition of the equipment can be monitored continuously or intermittently while it is operating. This gave birth to CBM, which is an alternative to the classic, time-driven approach of PM [20].Power electronics, programmable logic controllers (PLCs), computer controls, transponders and telecommunication systems are increasingly being introduced as substitutes for electromechanical systems. They offer the relative benefits of improved reliability, greater flexibility, compactness, less weight and lower cost. Fly-by-wire technology, utilising software - controlled electronic systems, has become commonplace for the current generation of aircraft. Correspondingly, flexible cells and computer-integrated systems are gaining acceptance in manufacturing [8]. The deployment of these new technologies is instrumental in enhancing a system's availability, improving the cost effectiveness of its operations and achieving better or innovative services for customers.

\section{THEORY AND BEHAVIOURAL MODELS}

\section{System's Performance}

The overall performance of a production system is determined by both quantitative and qualitative properties of the system. These characteristics are found for all its components and for the complete system. See, for example, Figure 3. It includes some parameters that can be defined as follows: 


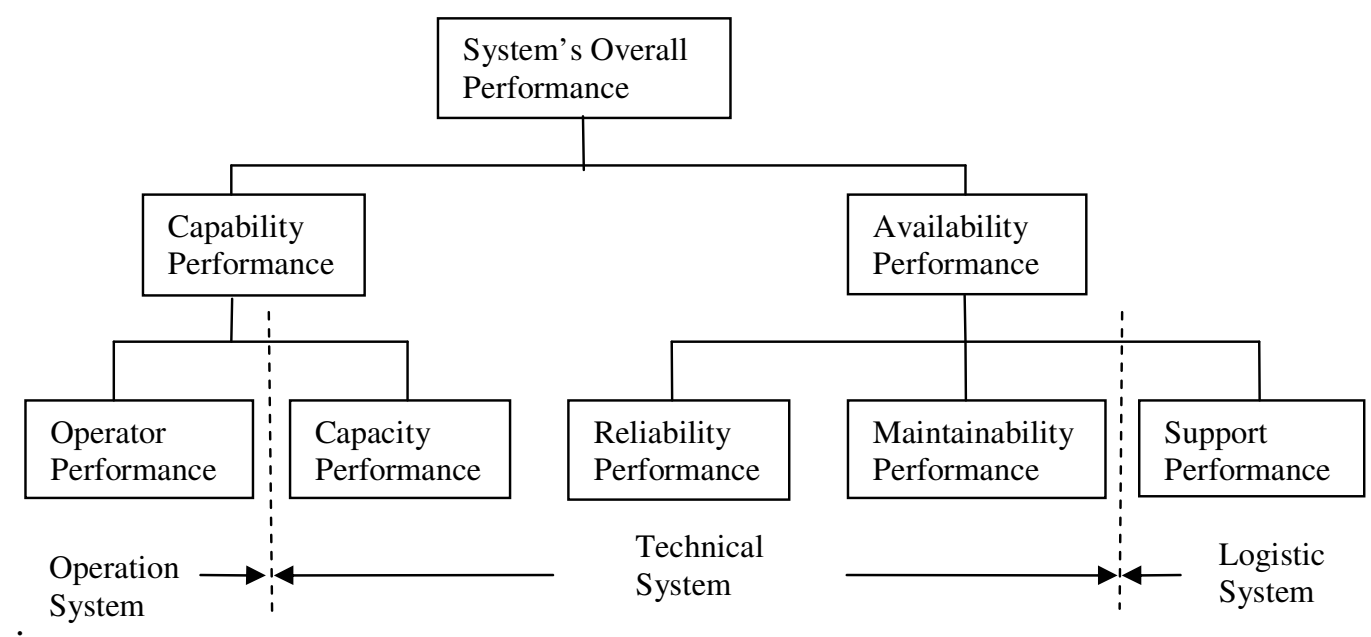

Figure 3: Contributory factors to the system's performance

- System's overall performance-the total production over a long period such as the lifetime of the system.

- Capability performance-the average production per unit time normally related to the rated capacity. If a plant operates at $100 \%$ capacity and the end-product is of $100 \%$ quality, the capability performance is 100 percent.

- Availability performance-the proportion of the total calendar time during which the equipment is active in its economic production condition. If the condition does not permit production at its fully-rated capacity, with the product quality at the specified level, the equipment is experiencing one or more failures and needs maintenance. When idle awaiting or during maintenance, the equipment is not available for production.

- Operational Performance-the capability of the operation to utilise the equipment relative to its maximum ability and availability. It will depend upon production planning and control, having well-trained personnel as well as the agreement of the safety department. Motivation of the individuals involved has a major influence on the operational performance.

- Capacity Performance-the ability of the equipment to produce, at the rated capacity, always satisfying the specified quality required.

- Reliability Performance-the ability of the equipment to perform the required function when operated. If the behaviour does not meet the specification, the equipment is suffering from a failure and needs maintenance. The reliability performance is normally described by the probability of reliability:-

$R(t)=\exp \left(-\frac{t}{M T B F}\right)=\exp (-\lambda t)$

where $\mathrm{t}=$ specified period, $\lambda=$ failure rate $=\frac{1}{\mathrm{MTBF}}$, and $\mathrm{MTBF}=$ mean time between failures.

- Maintainability Performance-properties determining the time to repair, which dictates the 'mean-time-to-repair', MTTR, which has little to do with the performance of the maintenance resources but is more dependent on the design and installation of the production equipment. 
Maintainability $(\mathrm{Mt})=\exp \left(-\frac{\mathrm{t}}{\mathrm{MTTR}}\right)=\exp (-\mu \mathrm{t})$

Where $\mu=$ repair rate $=1 / \tau$, and $\tau=$ restoration time or duration of outage, i.e. the MTTR $(=\tau)$

- Support Performance-the ability of the logistic support system, or maintenance system to provide back-up for the equipment when maintenance is required. It depends on the organisation of the maintenance procedures and the resources available (e.g. tools, personnel, skills and spares). The performance is measured in mean waiting time (MWT) or mean logistic downtime (MLDT). The theoretically correct method of computing the availability performance is to use the calendar time as 100 percent. This approach is mostly used for systems that are supposed to work around the clock, such as in some process industries.

The overall equipment effectiveness OEE is determined via:

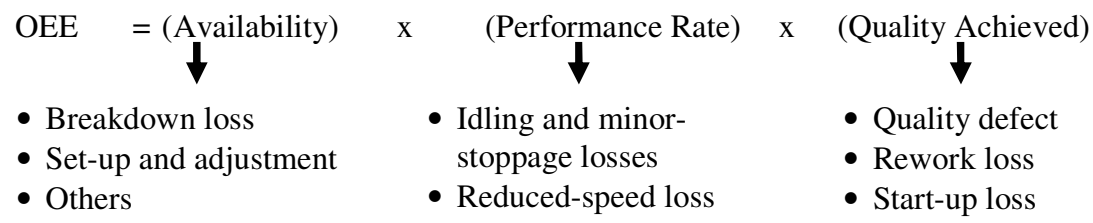

where:

- Availability (or Operating factor $)=($ Loading time - Down time $) /$ Loading time $=($ Uptime - Downtime $) /$ Uptime

- Performance Rate $=$ Output $/$ Loading time

- Quality Achieved = $($ Number of good products $) /$ Used input

$$
\begin{aligned}
& \text { Number of } \\
& \text { good products }
\end{aligned}=\text { Used input }-\left\{\begin{array}{l}
\begin{array}{l}
\text { Start-up } \\
\text { defects }
\end{array}+\quad \begin{array}{l}
\text { Process } \\
\text { defects }
\end{array} \\
+\begin{array}{l}
\text { Trail } \\
\text { products }
\end{array}
\end{array}\right\}
$$

Speed losses can be reduced and quality of end-product can be improved as shown in Table 1 and Figure 4 respectively.

Table 1: Strategy for reducing speed-losses: the actions are presented in this Table as ensuing in series, but in practice some would occur in parallel with one another.

\begin{tabular}{|l|l|}
\hline Action & Associated parameters and considerations \\
\hline $\begin{array}{l}\text { Determine present levels } \\
\text { of speed losses and their } \\
\text { consequences on the } \\
\text { considered activity }\end{array}$ & $\begin{array}{l}\text { Speed, bottleneck processes, downtime, frequency of } \\
\text { stoppages, condition-producing defects. }\end{array}$ \\
\hline $\begin{array}{l}\text { Check difference between } \\
\text { specifications and present } \\
\text { situation }\end{array}$ & $\begin{array}{l}\text { What are the specifications? Difference between standard } \\
\text { speed and present speed. Difference in speeds for } \\
\text { different products. }\end{array}$ \\
\hline $\begin{array}{l}\text { Investigate previous } \\
\text { pertinent problems }\end{array}$ & $\begin{array}{l}\text { Has the speed ever been greater? Types of problems, and } \\
\text { the measures taken to deal with them. Time trends with } \\
\text { respect to defect ratios, and speed losses and differences }\end{array}$ \\
\hline
\end{tabular}




\begin{tabular}{|c|c|}
\hline & in output from nominally-similar equipment \\
\hline $\begin{array}{l}\text { Investigate pertinent } \\
\text { processing theories and } \\
\text { principles. }\end{array}$ & $\begin{array}{l}\text { Problems relating to machining conditions, processing } \\
\text { conditions; and not achieving theoretically achievable, } \\
\text { theoretical values. }\end{array}$ \\
\hline $\begin{array}{l}\text { Investigate mechanisms } \\
\text { for achieving desired } \\
\text { output }\end{array}$ & $\begin{array}{l}\text { Rated output, load ratio, stress, revolving parts, and } \\
\text { specification of each part. }\end{array}$ \\
\hline List problems & $\begin{array}{l}\text { Identify conditions that should exist, compare with } \\
\text { operational conditions, problems with:- precision, } \\
\text { mechanisms, and processing theories. }\end{array}$ \\
\hline $\begin{array}{l}\text { Take remedial actions } \\
\text { against predictable } \\
\text { problems }\end{array}$ & $\begin{array}{l}\text { Compare predictable outcomes with present } \\
\text { achievements: take actions against predictable problems. }\end{array}$ \\
\hline \multicolumn{2}{|l|}{ Overcome the problems } \\
\hline \multicolumn{2}{|l|}{ Perform test runs } \\
\hline Confirm phenomena & $\begin{array}{l}\text { With respect to mechanical problems, quality of output } \\
\text { and change in cost of PM }\end{array}$ \\
\hline $\begin{array}{l}\text { Review analysis of } \\
\text { phenomena and cause- } \\
\text { and-effect relationships } \\
\text { carry out remedial actions }\end{array}$ & $\begin{array}{l}\text { Identify conditions producing phenomena related causes, } \\
\text { and eliminate them }\end{array}$ \\
\hline Perform test runs & \\
\hline
\end{tabular}


Deductive approach

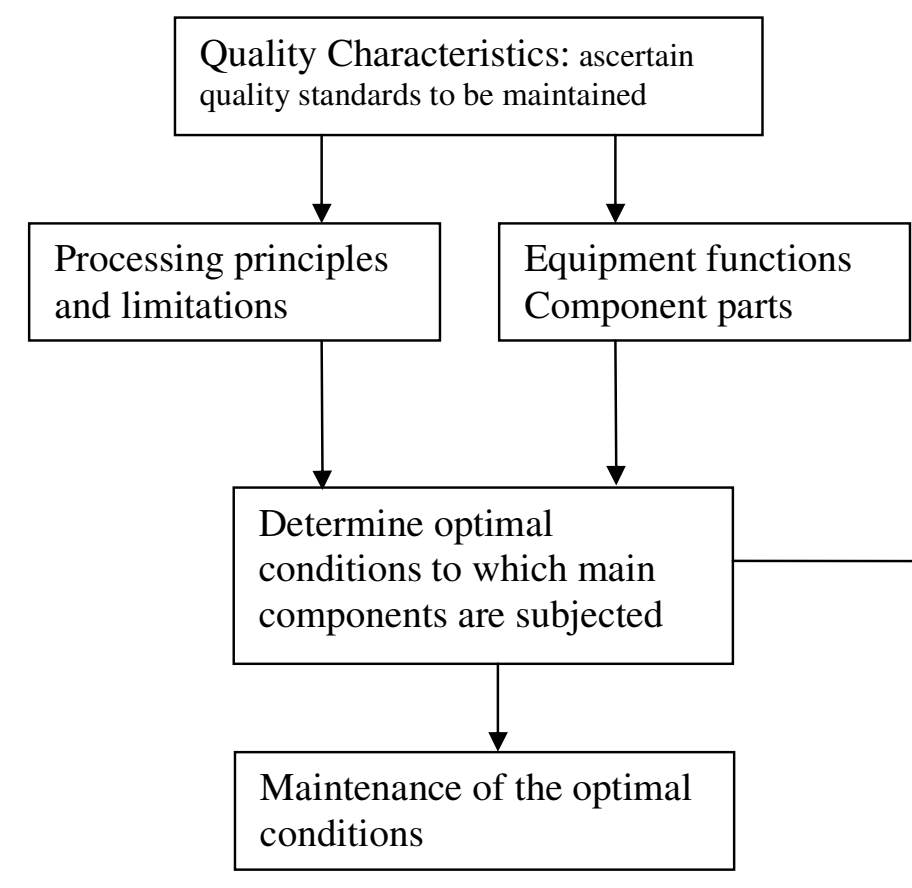

$\underline{\text { Analytic approach }}$

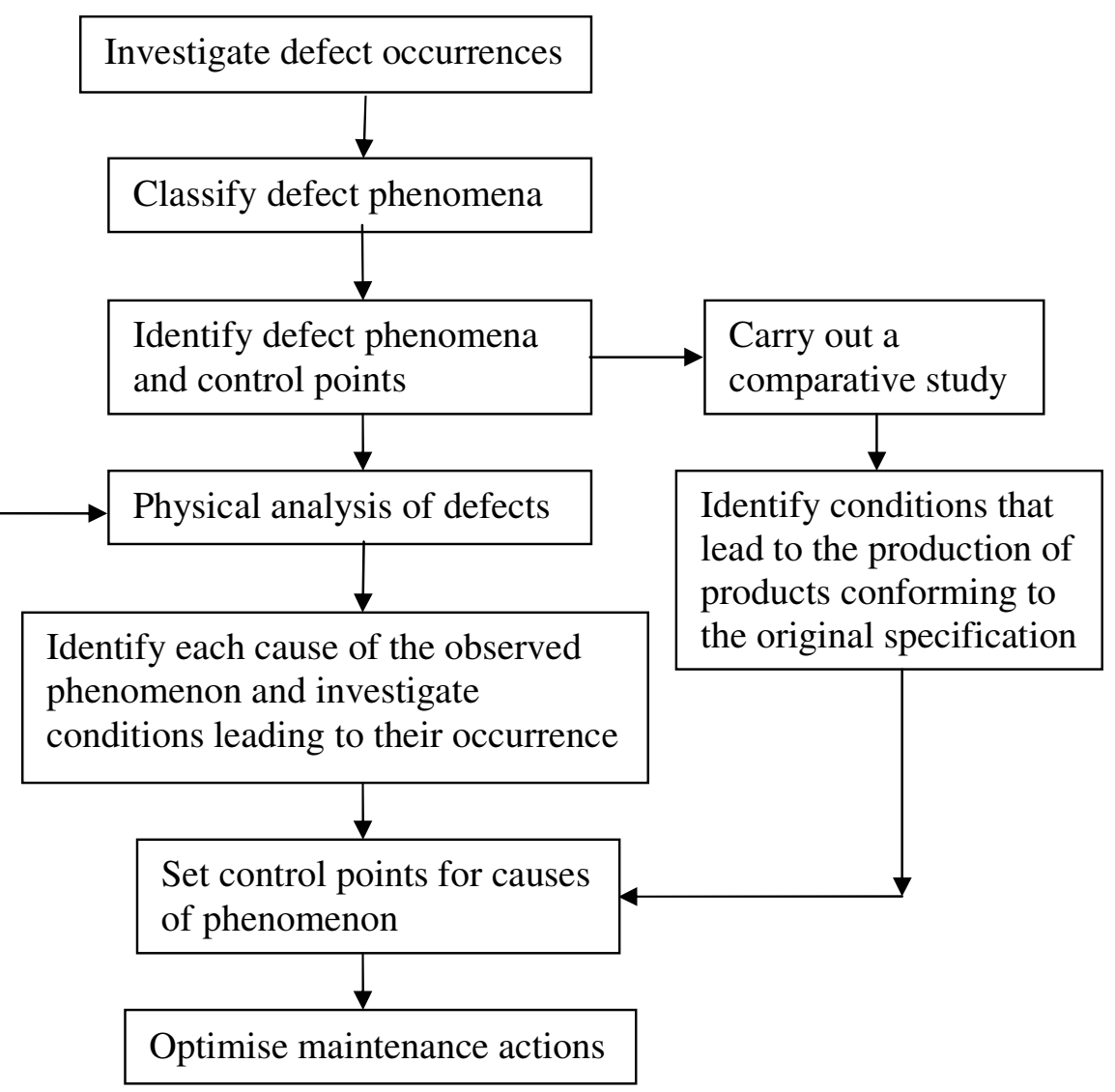

Figure 4. Improving the system's availability 
Set-up and Adjustment Losses

Some reasons for the values of these losses include:- confused procedures employed in the working methods, jigs and tools, technical problems, precision inadequate, supervision, inconsistent performance; and necessary adjustments to the operations not being implemented.

The causes of persistent losses may be due to:

- Remedial actions taken were unsuccessful as a result ofpoor maintenance work.

- The ad hoc measures taken provided no fundamental solution to the problem.

- No action was taken, and the extent and seriousness of the loss remain unclear.

- Characteristics of persistent losses were not understood, so only a poor followup on PM measures occurred and hence frequent stoppages ensued.

- Magnitude and cost of problem considered negligible or perhaps, at the other extreme, desirable improvements were assumed to be too costly.

- Typically, the reason for the persistent losses was unanticipated and hence remained unnoticed in cases of minor stoppages, speed loss, set-up and adjustment losses or start-up loss.

- Inadequate investigation of operational and engineering aspects: this sometimes arose when responsibility lay in more than a single department or with more than one person.

Poor equipment-management promotes persistent breakdowns. Poor maintenance results in lost production, poor end-quality of product and lack of customer satisfaction.

Many factors contribute to excellent maintenance performance. Consistency is achieved s a result of understanding well what needs to be done, following standard practices, working with excellent engineering support, and providing inspiring training for the personnel involved.

\section{CONCLUSION}

As Nigerian industrial managers are seeking to inculcate a competitive outlook in their manufacturing industries, they need to posses a culture that deals more effectively with rapid changes. The introduction of TPM will help in achieving this. TPM is predicated by the challenge of seeking to do things better - hence dealing effectively with change (often requiring rapid alteration) needs to become a way of life within manufacturing organisations. The willingness of employees within an organisation to accept "change" for the better is an essential prerequisite for successfully implementing TPM. Their degree of eagerness to embrace "change" determines the rate of progress towards that goal. TPM can only succeed in an organisation that is committed to provide the necessary training and time to monitor the success or failure of the ensuing improvement initiatives. For the full implementation and achieving sustainability of TPM in Nigeria, using the proposed models and strategies, there should be a new thoughtware and recalibration of what is expected in existing organisations: this should be self-audited and benchmarked against world-class industries with similar product lines. 
With competition in manufacturing industries rising relentlessly, TPM can be the maintenance philosophy prevents the failure of an organisation. It is a maintenance programme that works with TQM and lean management. However, the employees must be appropriately trained, empowered and convinced that TPM is sustainable and the management should be totally committed to the programme. Nigerian industrial managers must move away from traditional reactive maintenance procedures to implementing more proactive maintenance processes. By better planning of maintenance schedules, less energy and effort are wasted, improved productivity occurs and greater financial surpluses are achieved.

\section{References}

1. Ohno, T. (1988) Toyota Production-System, American Technical Publishers Ltd, Herts. UK.

2. Shingo, S. (1991) A Revolution in Manufacturing: the SMED System, Mass Productivity Press, Cambridge.

3. Deming, W.E. (1982) Out of Crisis, Centre for Advanced Engineering Study, Cambridge, Mass: MIT, pp 465-474.

4. Juran, J.M and Gryna, F.M. (1993) Quality Planning and Analysis, $3^{\text {rd }}$ ed., McGraw Hill, New York.

5. Moubray, J. (2000) http://www.maintenanceresources.com

6. Tsang, A.H.C, Jardine, A.K.S., Cambell, J.D. and Picknell, J.V. (2000), Reliability-centred maintenance: a key to maintenance excellence, City University of Hong Kong, Hong Kong (internet publication).

7. Bekkers, P (2002) The productivity factory, http://www.tpfeurope.com

8. Tsang, A.H.C. (2002) Strategic dimensions of maintenance management, Journal of Quality in Maintenance Engineering, Vol 80, No 1, pp 7-39.

9. Nakajima, S. (1988) Introduction to TPM, Productivity Press, Cambridge, MA.

10. Robert, J. (2002) Total productive maintenance (TPM), JackRobert@TAMU_Commerce.edu

11. Lee, K. (2002) Total Productive Maintenance (TPM), http://www.maint2k.com

12. Hughes, B. (2002) Business-centred maintenance, info@maintenanceresources.com

13. Agyris, C. (1998) Empowerment: the emperor's new clothes, Harvard Business Review, Vol 76, No 3, pp 98-105.

14. Campbell, J.D. and Jardine, A.K.S. (2001) Maintenance Excellence: optimising equipment life-cycle decisions, Marshall Dekker, New York.

15. Simon, R. (1995) Levers of control: how managers use innovative controlsystems to drive strategic renewals, Harvard Business School Press, Boston, MA. 
16. Tsang, A.H.C (1998) A strategic approach to managing maintenance performance, Journal of Quality in Maintenance Engineering, Vol. 4, No.2, pp 87-94

17. Kaplan, R.S. and Norton, D.P (1996) The Balanced Scorecard, Harvard Business School Press, Boston, MA.

18. Tsang, A.H.C and Chan, P.K. (2000) TPM implementation in China: case study, International Conference on Quality and Reliability, Vol 17, No 2, pp 144-57.

19. McQueen, G. (1999) The buzz on benchmarking: compare your performance with the best to improve production and out cost, Maintenance Technology Magazine (http://www.maintenanceresources.com)

20. Tsang, A.H.C (1995) Condition-based maintenance: tools and decision making, Journal of Quality in Maintenance Engineering, Vol. 4, No 2, pp 317. 